\title{
Research on Government Responsibility in Rural Sports Fundamental Public Service Development
}

\author{
Yuan $\mathrm{Li}^{*}$
}

Institute of Physical Education, Huainan Normal University, Huainan 232038, Anhui, China

\begin{abstract}
In sports public services system construction, rural sports fundamental public service construction and development are the most import parts; rural development restricts whole system's construction. And government as one of rural leaders, its functions among them cannot be ignored. The paper takes government responsibility in rural sports fundamental public service as main research direction, analyzes rural sports fundamental public service construction. Firstly, it researches on sports fundamental public service proportions of rural public cultural facilities, investigates government responsibility in rural sports fundamental public service, and carries out reliability analysis. Secondly, it utilizes goal programming and maximal principle, establishes government functions analytical model on the basis of rural fundamental sports public service, by quantitative analysis, it gets conclusions that in rural sports fundamental public service research, government most important function is perfecting sports public facilities, secondly is implementing legal protection to peasants sports public service rights, and providing sufficient sports activities funds support.
\end{abstract}

Keywords: Government responsibility, maximal principle, public service, reliability analysis.

\section{INTRODUCTION}

In the general background of integration of urban and rural development, urban and rural sports development is also an important factor that restricts its progress. In urban and rural sports development process, due to economy and other special conditions, village's sports development always affect urban and rural sports mutual improvement pace [1].

Every village's development level is different; its process in sports also has obvious difference. Hou Xue-Jie in the article "Rural sports difference study under different developed degrees", by researching on different developed degrees villages situation, she analyzed obvious differences existed in sports field [2]. Through investigating individual economic development levels villages, sports facilities construction and government management situation, the article analyzed data, and finally presented that rural sports development and its developed degrees were significantly related, villages that were more developed, their sports construction were also relative better, and rural residents sports awareness also strengthened accordingly [3].

Community is a good carrier to sports development, rural community as rural resident gathering place is even an optimal place for sports fitness.

Tao $\mathrm{Li}$ in the article "Chinese rural community sports public service situation and system construction", by researching on rural community sports public service development current situation, he studied its service system construction problems, and put forward systematic sports service system was helpful for rural resident sports positivity's improvement, their sports exercises enthusiasm's stimulation, and further also propelling to rural sports public service system construction to a certain degree [4].

Urban and rural sports always is a focus that cannot be avoided in sports development process, Pang Li in the article "Urban and rural fundamental public service equalization propelled public finance system research", he took urban and rural sports fundamental public service as research objects, carried out contrastive analysis, pointed out that public finance system was foundation for ensuring urban and rural fundamental public service development, and meanwhile was also base that propelled to urban and rural sports development integration and equalization [5].

The paper works on government functions important roles in rural sports fundamental public service development, by the perspective of statistics, it makes quantitative research on government roles importance in propelling to village fundamental public service system construction, and puts forward corresponding suggestions on rural sports fundamental public service current situation.

\section{MODEL ESTABLISHMENT}

Village is a part that slowly develops in Chinese sports; its development slowness not only suffers economic influence, but also has great connections with rural villagers' sports awareness. Besides, government roles that play in rural sports construction are also very important.

Below Table 1 is investigation of Chinese rural public cultural facilities construction, by investigating and contrasting sports fundamental public service proportion in rural public cultural construction, and further research on rural sports fundamental public service development situation, and then put forward countermeasures for problems. 
Table 1. Rural public cultural facilities construction investigation.

\begin{tabular}{|c|c|c|c|}
\hline & Percentage\% & Percentage\% \\
\hline \hline Public library & $9.4 \%$ & Drama stage, theatrical stage & $0.8 \%$ \\
\hline Aged activity room & $13.7 \%$ & Projector room & $2.7 \%$ \\
\hline Youth activity center & $3.6 \%$ & Public internet bar & $1.5 \%$ \\
\hline Fitness facility & $8.6 \%$ & Ancestral hall & $3.2 \%$ \\
\hline Chess and card room & $8.0 \%$ & Temple & $0.9 \%$ \\
\hline Basketball and other balls facilities & $8.5 \%$ & Church & $10.1 \%$ \\
\hline Wired radio & $8.0 \%$ & Cable television & $3.7 \%$ \\
\hline Newspaper area & $6.5 \%$ & Individual cultural room, library & $1.2 \%$ \\
\hline Cultural activities center & $4.9 \%$ & Others & \\
\hline
\end{tabular}

Table 2. Government responsibility in rural sports fundamental public service.

\begin{tabular}{|c|c|}
\hline & Percentage $\%$ \\
\hline \hline Provide multilevel, all-around compulsory sports knowledge education & $52.1 \%$ \\
\hline Carry out legal protection to peasants sports public service right & $79.8 \%$ \\
\hline Implement village and city equal sports public service treatment sharing & $71.0 \%$ \\
\hline Organize sports activities & $75.4 \%$ \\
\hline Provide sufficient sports activities funds support & $76.7 \%$ \\
\hline Perfect sports public facilities & $88.2 \%$ \\
\hline
\end{tabular}

By above analysis, it is clear that in rural public cultural facilities, sports fundamental public service proportion is not very big, fundamental public service type is mainly aged activity room, youth activity center, fitness facilities, which includes ball kinds and other facilities, besides there is chess and card room and so on. Service types are relative more, but it still is short of sports clubs and other sports services with stronger sense of organizational discipline and stronger sports atmosphere.

\section{Government Functions in Rural Sports Fundamental Public Services}

In rural fundamental public service development history, government plays an irreplaceable role. For village, each aspect funds sources are quite limited, and rural resident awareness of consciously going in for physical exercises and sports activities is lower, sports behaviors and ability are poorer with regard to cities. Government plays a very important role here, government compelling force and advocating force can propel to rural resident sports enthusiasm so that impel rural sports development.

Below Table 2 is investigation of government functions on rural sports fundamental public service, make initial analysis of the investigation, define its reliability, relative analysis is as Fig. (1).

To check above investigation reliability, firstly carry out reliability analysis of it.

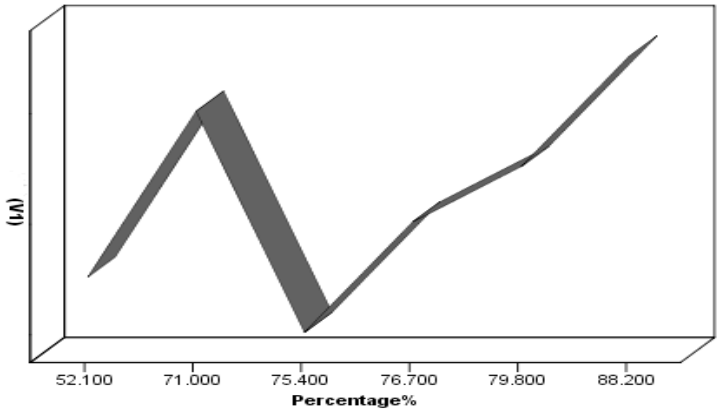

Fig. (1). The government responsibilities in rural sports basic public services.

Reliability analysis: It is well known that reliability analysis is to test things reliability. In reliability analysis,

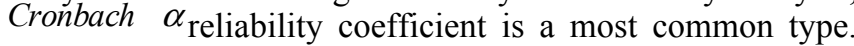
Its expression is:

$$
\alpha=(k /(k-1)) \times\left(1-\left(\sum S_{i}^{2}\right) / S_{T}^{2}\right.
$$

In formula, $k$ : Sample sum in scale

$S_{i}^{2}:$ Topic i scores variance

$S_{T}^{2}:$ All topics total scores variance

Besides, reliability coefficient evaluation principle is as following Table 3: 
Table 3. Reliability analysis criterion.

\begin{tabular}{|c|c|}
\hline Reliability & Cronbach $\alpha$ coefficient \\
\hline \hline Not reliable & Cronbach $\alpha<0.3$ \\
\hline Barely reliable & $0.3 \leq$ Cronbach $\alpha<0.4$ \\
\hline Reliable & $0.4 \leq$ Cronbach $\alpha<0.5$ \\
\hline Quite reliable( most common) & $k=1,2 \cdots, q$ \\
\hline Quite reliable(second-rate common) & $0.7 \leq$ Cronbach $\alpha<0.9$ \\
\hline Very reliable & $0.9 \leq$ Cronbach $\alpha$ \\
\hline
\end{tabular}

Table 4. Reliability statistics.

\begin{tabular}{|c|c|c|}
\hline Cronbach's Alpha & Standardized terms-based Cronbachs Alpha & Number of terms \\
\hline \hline .586 & .977 & 6 \\
\hline
\end{tabular}

Table 5. Total statistics of terms.

\begin{tabular}{|c|c|c|c|c|}
\hline & $\begin{array}{c}\text { Deleted scale average value } \\
\text { of term }\end{array}$ & $\begin{array}{c}\text { Deleted scale variance of } \\
\text { term }\end{array}$ & $\begin{array}{c}\text { Corrected term total correla- } \\
\text { tion }\end{array}$ & Square of multiple correlation \\
\hline \hline Percentage\% & 237.66667 & 2815.867 & .956 & .913 \\
\hline
\end{tabular}

By comparing above Cronbach $\alpha$ coefficient size, observe system reliability.

Utilize SPSS software, carry out reliability analysis of Table $\mathbf{2}$ data, it gets reliability analysis data Table $\mathbf{4}$ and Table 5 regarding investigation statistics of government responsibility in rural sports fundamental public service.

By above analysis table, it can get: Cronbach $\alpha=0.586$, according to reliability analysis criterion,

When $0.5 \leq$ Cronbach $\alpha<0.7$,

Reliability is very reliable (most common), therefore it is clear that Table 2 statistics investigation data has certain reliabilities that can be used to do next step analysis.

\section{OPTIMAL PRINCIPLE-BASED RURAL SPORTS FUNDAMENTAL PUBLIC SERVICE'S GOVERN- MENT RESPONSIBILITY RESEARCH}

Utilizing goal programming method, and on the basis of above reliability analysis, it makes analysis of Table 2 data and then defines government relative important responsibilities and functions in rural sports fundamental public service construction.

\section{Guiding Thought}

Goal programming objective function general fundamental form is:

(1) Positive and negative deviation variable tries to be small so that just arrives at goal value: $\min z=f\left(d^{+}+d^{-}\right)$

Positive deviation tries to get small, no need to arrive at goal value

$$
\min z=f\left(d^{+}\right)
$$

Negative deviation tries to get small, above goal value and surplus amount is not limited

$$
\min z=f\left(d^{-}\right)
$$

Priority factor: $P_{1}, P_{2}, \cdots$, and it has $P_{k} \gg P_{k+1}, k=1,1, \cdots, q$, represents that $P_{k}$ has bigger priority than $P_{k+1}$.

Goal programming general mathematical model:

Known that $x_{j}(j=1,2, \cdots, n)$ is decision variable function, it totally has $m$ pieces of constraints, and $l$ pieces of weak goal constraints, its goal programming constraints deviation variable is $d^{+}, d_{i}^{-}(i=1,2, \cdots, l)$.Assume that it has $q$ pieces of priorities that are respectively $P_{1}, P_{2}, P_{3}, \cdots, P_{q}$. In the same priority $P_{k}$, weights are different that are respectively $\omega_{k j}^{+}$, $\omega_{k j}^{-}(j=1,2, \cdots, l)$.Therefore goal programming general mathematical form is:

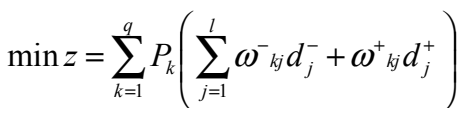




$$
\left\{\begin{array}{l}
\sum_{j=1}^{n} a_{i j} x_{j} \leq(=, \geq) b_{i}, i=1, \cdots, m \\
\sum_{j=1}^{n} c_{i j} x_{j}+d_{i}^{-}-d_{i}^{+}=g_{i}, i=1, \cdots, l \\
x_{j} \geq 0, j=1,2, \cdots, n \\
d_{i}^{-}, d_{i}^{+} \geq 0, i=1,2, \cdots, l
\end{array}\right.
$$

\section{Goal Programming Data Processing}

According to above goal programming guiding thought, carry on data processing with government responsibility data statistical table, here adopts sequential algorithm here. Its main process is as following:

For $k=1,2 \cdots, q$, it solves:

$\min z=\sum_{j=1}^{l} P_{k}\left(\sum_{j=1}^{l} \omega_{k j}^{-} d_{j}^{-}+\omega_{k j}^{+} d_{j}^{+}\right)$

$\sum_{j=1}^{n} a_{i j} x_{j} \leq(=, \geq) b_{i}, i=1, \cdots, m$

$\sum_{j=1}^{n} c_{i j} x_{j}+d_{i}^{-}-d_{i}^{+}=g_{i}, i=1, \cdots, l$

$\sum_{j=1}^{l}\left(\omega_{s j}^{-} d_{j}^{-}+\omega_{s j}^{+} d_{j}^{+}\right) \leq z_{s}^{*}, s=1,2, \cdots, k-1$

$x_{j} \geq 0, j=1,2, \cdots, n$

$d_{i}^{-}, d_{i}^{+} \geq 0, i=1,2, \cdots, l$

Among them, optimal value is $z_{k}^{*}$

Therefore, it gets corresponding goal programming model :

$\min z=P_{1} d_{1}^{-}+P_{2}\left(d_{2}^{+}+d_{2}^{-}\right)+P_{3}\left(3 d_{3}^{+}+3 d_{3}^{-}+d_{4}^{+}\right)+P_{4}\left(3 d_{4}^{+}+3 d_{4}^{-}+d_{5}^{+}\right)$

$0.521 x_{1}+0.798 x_{2}+0.710 x_{3}+0.754 x_{4}+0.767 x_{5}+0.882 x_{6}=1$

$x_{1}, x_{2}, \cdots, x_{i}, d_{i}^{+}, d_{i}^{-} \geq 0, i=1,2, \cdots, 6$

Calculate above objective function by MATLAB software, and further get goal programming optimal solution is: $z^{*}=(2,6,5)$, and the lowest percentage is $76.0 \%$. Therefore, it is clear that in rural fundamental sports public service, government most important functions are perfecting sports public facilities, secondly is implementing legal protection to peasants sports public service rights, and providing sufficient sports activities funds support. To further research on the uppermost important function of them. Now it utilizes maximal principle to make deepen analysis of them, and gets conclusions, process is as following.

\section{Maximal Principle-based Government Functions Analysis}

According to above question assumptions, it can get state equation of maximized number of participants when each factor percentage changes are permitted: $\left\{\begin{array}{l}\frac{d x\left(t_{1}\right)}{d t_{1}}=-m(t)+g(t) u(t) \\ x(0)=x_{0}\end{array}\right.$

At first, write down question's Hamiltonian function:

$H[p x(t)-u(t)] e^{-\delta t}+\lambda[-m(t)+g(t) m(t)]$

By:

$\left\{\begin{array}{l}\frac{d \lambda(t)}{d t}=-H_{x}=-p e^{-\delta t} \\ \lambda\left(t_{f}\right)=\varphi_{x\left(t_{f}\right)}=e^{-\delta t_{f}}\end{array}\right.$

It solves:

$\lambda(t)=\left(1-\frac{p}{\delta}\right) e^{-\delta t_{f}}+\frac{p}{\delta} e^{-\delta t}$

In the following, utilize maximal principal to solve

$u^{*}(t)$

For:

$H=p x(t) e^{-\delta t}-\lambda m(t)+\left[\lambda g(t)-e^{-\delta t}\right] u(t)$

Obviously, $H$ is linear function of $u$, therefore it can get:

$u^{*}(t)= \begin{cases}U, & \lambda g(t)-e^{-\delta t}>0 \\ 0, & \lambda g(t)-e^{-\delta t}<0\end{cases}$

Or:

$u^{*}(t)=\left\{\begin{array}{lc}U, & {\left[\left(1-\frac{p}{\delta}\right) e^{-\delta t_{f}}+\frac{p}{\delta} e^{-\delta t}\right] g(t)-e^{-\delta t}>0} \\ 0, & {\left[\left(1-\frac{p}{\delta}\right) e^{-\delta t_{f}}+\frac{p}{\delta} e^{-\delta t}\right] g(t)-e^{-\delta t}<0}\end{array}\right.$

For breaking point $t_{s}$, it should meet:

$\left[\left(1-\frac{p}{\delta}\right) e^{-\delta t_{f}}+\frac{p}{\delta} e^{-\delta t}\right] g(t)-e^{-\delta t}=0$

That is:

$\left[\frac{p}{\delta}-\left(\frac{p}{\delta}-1\right) e^{-\delta t_{f}}\right] g(t)-1=0$

And then it can solve $t_{s}$ :

In the subject, set

$x(0)=0.48, U=1, m(t)=2, p=0.1, \delta=0.05, g(t)=\frac{2}{(1+t)^{\frac{1}{2}}}$

Therefore it can get the formula of $t_{s}$ as

$\left(1+t_{s}\right)^{\frac{1}{2}}=4-2 e^{0.05\left(t_{s}-t_{f}\right)}$.

When $t<t_{s}, u^{*}(t)=U=1$, state equation now is: $\frac{d x}{d t}=-2+\frac{2}{(1+t)^{\frac{1}{2}}}$

When $t<t_{s}, u^{*}(t)=0$, state equation now is 


$$
\frac{d x}{d t}=-2
$$

So when $t>t_{s}$

it has: $\int_{0}^{t} \frac{d x}{d t}=\int_{0}^{t_{s}}\left[-2+\frac{2}{(1+t)^{\frac{1}{2}}}\right] d t+\int_{t_{s}}^{t}(-2) d t$

It solves:

$x(t)=4\left(1+t_{s}\right)^{\frac{1}{2}}+96-2 t$

$t_{f}=2\left(1+t_{s}\right)^{\frac{1}{2}}+28$

It gets:

$t_{s}=0.70, t_{f}=0.882$.

By above analysis, it is clear that perfect sports public facilities is main function that government works in rural sports fundamental public service, secondly is to implement legal protection to rural sports public service right and provide sufficient sports activities funds support. It is similar to Table 2 investigation result, which indicates government should strengthen sports fundamental public facilities construction, perfect safeguard mechanism of rural resident right, and provide sufficient funds support for rural resident sports activities.

\section{Rural Resident Satisfaction with Sports Public Facilities}

Whether government implements his responsibility, the most direct reflection is rural resident satisfaction. Therefore, on the basis of above analysis, it further makes statistical analysis of rural resident satisfaction. By satisfaction index, specific research on the result of government work, relative data and analysis can reference Table 6 and Fig. (2).

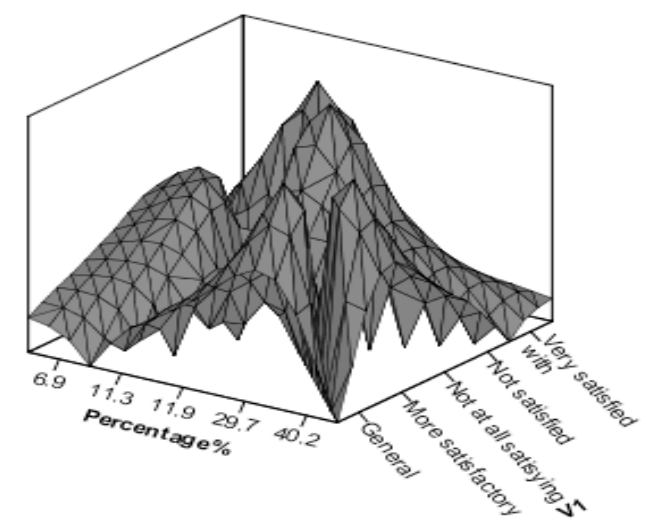

Fig. (2). Rural residents' satisfaction.

By above analysis, it can get conclusions that rural resident are relative satisfied with government work in sports fundamental service, but there are still $6.9 \%$ residents are very dissatisfied with them. It indicates that our government still hasn't done a good job in rural sports fundamental service that still has lots of drawbacks, so they should proactive go to village, learn aspirations of rural residents, and effectively implement the work according to rural residents' demands.
Table 6. Rural resident satisfaction.

\begin{tabular}{|c|c|c|}
\hline & Frequency & Percentage\% \\
\hline \hline Very satisfied & 242 & 11.3 \\
\hline Relative satisfied & 862 & 40.2 \\
\hline Ordinary & 638 & 29.7 \\
\hline Not so satisfied & 255 & 11.9 \\
\hline Very dissatisfied & 148 & 6.9 \\
\hline
\end{tabular}

\section{CONCLUSION}

According to above research and statistical analysis, it gets following conclusions: (1) In rural public cultural facilities construction, sports fundamental public service proportion is not so big, basic public service types mainly are aged activity room, youth activity center, fitness facilities, which includes ball kinds and other facilities, besides there is chess and card room and so on. Service types are relative more, but it still has a big gap with cities. (2) In rural sports fundamental public service's government responsibility investigation, by reliability analysis, it is clear that investigation result has reliability, and on the basis of the result, it further carries out optimal principle and maximal principle analysis, and further put forward that in rural fundamental public service, government most important function is perfecting sports public facilities, secondly is implementing legal protection to peasants sports public service rights, and providing sufficient sports activities funds support. (3) Based on above analysis, it also proceeds with further supplement analysis, carries out statistical analysis of rural resident satisfaction with sports public facilities, and then observes whether government effectively implements their work or not, and points out that rural residents are basically satisfied with government work in sports fundamental service, but government should continue to implement rural fundamental public services according to rural residents' demands.

\section{CONFLICT OF INTEREST}

The authors confirm that this article content has no conflict of interest.

\section{ACKNOWLEDGEMENTS}

The work is supported by Humanities and science research project of colleges and universities in Anhui province: SK2014A383.

\section{REFERENCES}

[1] Y. Chen, and G. Ma, "An empirical study on community sports service residents' satisfaction index model," China Sport Science and Technology, vol. 45, no. 4, 2009.

[2] Y. He, and M, Xu, "Theoretical and empirical study on evaluation mode of sports service satisfaction degree in city community," Journal of Wuhan Institute of Physical Education, vol. 41, no. 11, pp. 40- 42, 2007.

[3] B. Liu, S. Hu, H. Xu, and J. Gao, "Indices of the equality of essential public health services in China," Chinese Journal of Health Policy, vol. 2, no. 6, pp. 13-17, 2009. 
[4] D. Zhang, and M. Li, "Studies on evaluation index system of public sports facilities development level in China," China Sport Science, vol. 33, no. 4, pp. 3-23, 2013.
[5] J. Zhan, and Y. Wu, "The evaluation index system of extracurricular sports activities in secondary schools in shanghai under the background of "sunshine sports"," Journal of Shanghai Physical Education Institute, vol. 22, no. 6, pp. 80-82, 2012.

Received: May 26, 2015

(C) Yuan Li; Licensee Bentham Open.

This is an open access article licensed under the terms of the (https://creativecommons.org/licenses/by/4.0/legalcode), which permits unrestricted, noncommercial use, distribution and reproduction in any medium, provided the work is properly cited. 